\title{
Study of Two Fractions versus Three Fractions of High Dose Rate Brachytherapy in Locally Advanced Carcinoma of Uterine Cervix after Pelvic Concurrent Chemoradiotherapy
}

\author{
Israt Jahan, MBBS, MD ${ }^{1 *}$, Abdul Bari, MBBS, MPhil², Prof Sarwar Alam, MBBS, DMRT ${ }^{3}$, Niaz Mostafa, MBBS,
} FCPS, MRCP ${ }^{4}$

${ }^{1,4}$ Department of Radiation Onology CMH, Dhaka, Bangladesh

${ }^{2},{ }^{3}$ Department of Onology Bangabandhu Sheikh Mujib Medical University BSMMU, Dhaka, Bangladesh

DOI: $10.36347 /$ sjmcr.2020.v08i12.013

| Received: 30.11.2020 | Accepted: 14.12.2020 | Published: 26.12.2020

*Corresponding author: Israt Jahan

\section{Abstract}

Original Research Article

Uterine cervical cancer is the commonest form of gynecologic malignancy in Bangladesh and South east Asia. The aim of this study was to compare the treatment outcome and complications following treatment with 9 Gy (gray) in two fractions of intracavitery radiotherapy (ICRT) following external beam radiotherapy (EBRT) with 7 Gy in three fractions of ICRT. A prospective randomized study carried out in different tertiary hospitals of Bangladesh during the period of 2015 to 2016 with a number of 61 patients evaluated, all patients received EBRT 50 Gy in 25 fraction of $2 \mathrm{~Gy}$ per fraction over a period of 5 weeks and inj. Cisplatin $40 \mathrm{mg} / \mathrm{m}^{2}$ weekly. Then ICRT weekly two fractions with 9 Gy per fraction in arm A and three fractions of $7 \mathrm{~Gy}$ to arm B was delivered. At 3 years follow up, complete remission was $77 \%$ and $73 \%$ respectively for arm A and arm B. The overall complete response was $75 \%$. The common toxicities associated with treatment were bladder and rectal toxicities, skin reaction and hematologic complications which were managed well. During follow up after 3 years, there was no grade 3 or 4 toxicities and rectal and bladder toxicities were similar in both arms. This study showed that after standard EBRT total dose of 18 Gy ICRT in two fractions of 9 Gy over 2 weeks is equally effective in local control with acceptable toxicities in comparison with a total dose of 21 Gy in three fractions of 7 Gy ICRT.

Key words: Brachytherapy, Gray, Carcinoma cervix, Treatment response, Toxicity.

Copyright $(\mathcal{C} 2020$ The Author(s): This is an open-access article distributed under the terms of the Creative Commons Attribution 4.0 International License (CC BY-NC 4.0) which permits unrestricted use, distribution, and reproduction in any medium for non-commercial use provided the original author and source are credited.

\section{INTRODUCTION}

Uterine cervical cancer is the fourth most common cancer in women worldwide, and the seventh overall. A large majority (around 85\%) of the global burden occurs in the less developed regions, where it accounts for almost $12 \%$ of all female cancers. There were an estimated 266,000 deaths from cervical cancer worldwide in 2012, accounting for $7.5 \%$ of all female cancer deaths. Almost nine out of ten $(87 \%)$ cervical cancer deaths occur in the less developed regions [1].

In Bangladesh and many other developing countries, unfortunately the incidence and mortality rates of carcinoma uterine cervix remains high, predominantly due to late detection. There is no nationwide data of cancer in Bangladesh, but according to the cancer registry report of National Institute of Cancer Research and Hospital (2014) carcinoma of uterine cervix is the second leading cancer among women, some hospital based registry has shown that about 25,000 women are diagnosed as new case of carcinoma uterine cervix every year [2]. More than $80 \%$ cases usually present at an advanced stage with a high mortality rate. According to WHO report, age standardized incidence of cervical cancer in Bangladesh is 29.4 per lac women. Mortality from this disease is 17.9 per lac women. One third cervical cancer cases of world are found in South-Asian region, especially in India, Bangladesh and Pakistan [3]. In Bangladesh this is the commonest gynecological cancer, about $70 \%$ of the hospital cases of gynecological cancer are cervical cancer $[2,4]$.

Primary radiotherapy with concurrent chemotherapy is the treatment of choice for locoregionally advanced disease with a careful balance of pelvic EBRT and intracavitary brachytherapy, and must be administered at high doses (>80 -90Gy) and in a short time ( $<55$ days) with the best technological resources available[5]. 
Treatment duration of cervical carcinoma with radiotherapy (EBRT and ICRT) should be as short as possible (within 8 weeks), and any planned or unplanned interruptions or delays should be avoided. Overall treatment time should not exceed 56 days including brachytherapy and should ideally be 49 days or less. Lower pelvic tumor control and survival rates are observed in invasive carcinoma of the uterine cervix when the overall treatment time in a course of irradiation is prolonged [6].

Bangladesh is a developing country with a dense population. In Bangladesh $80 \%$ of carcinoma of uterine cervix presents at a fairly advanced stage with a high mortality rate. We have a variety of problems in managing cervical cancer including patient load, which is very high due to inadequate number of radiotherapy centre with lesser number of brachytherapy machine. So, if decreasing the insertion of HDR brachytherapy from 3 to 2 fractions gives similar result, then it will help patients by reducing treatment cost and decreasing repeated attendance in hospital, as well as reduction in patient load in radiotherapy centres to some extent and more patients will get chance of treatment.

So, the objective of this study was to observe and compare the local control of disease and complications following treatment of locally advanced carcinoma cervix with two fractions of HDR brachytherapy after standard concurrent chemoradiation and compare it with brachytherapy of three fractions.

\section{Materials ANd Methods}

It was a prospective randomized study and conducted in Department of Oncology, Bangabandhu Sheikh Mujib Medical University (BSMMU), Shahbag, Dhaka and Department of Radiation Oncology, National Institute of Cancer Research and Hospital (NICRH), Mohakhali, Dhaka, Bangladesh. The duration was three year from December 2015 to December 2018.

A total 70 patients with clinically diagnosed and histologically proven locally advanced squamous cell carcinoma of the uterine cervix (Stage IIB-Stage IVA) were selected as sample and finally total 61 patients who met the study criteria were evaluated and analyzed. The aim of this study was to see the local control of different fractionation of brachytherapy as the primary outcome and secondary outcome was to compare the toxicities.

Ethical approval was taken from the institutional review board (IRB) of BSMMU (No. BSMMU/2015/13577 dated 14-11-2015), informed consent was taken from each patient before enrolling in the study.

For radiotherapy the target volume was whole pelvis encompassing the extent of primary tumor and the pelvic lymph nodes. During EBRT whole pelvis was treated with 2 Gy per fraction, 5 days in a week with a total dose of 50 Gy for 5 weeks in a Cobalt 60 teletherapy machine with SSD of $100 \mathrm{~cm}$, Inj. cisplatin $40 \mathrm{mg} / \mathrm{m}^{2}$ was given weekly to the patients on days 1,8 , 15, 22 and 29. After EBRT, all the patients of both arms were treated with HDR ICRT. A dose of 9 Gy per fraction, 2 fractions in 2 weeks for arm $\mathrm{A}$ and 7 Gy per fraction, a total of 3 fractions over 3 weeks for arm B to the point-A were given. A total ICRT dose of $18 \mathrm{~Gy}$ and 21 Gy were delivered for arm A and B respectively. The bladder and rectal dose was calculated in bladder and rectal point.

RECIST (response evaluation criteria for solid tumors) criteria was followed to assess the treatment response. For toxicity assessment, 'Toxicity criteria of the Radiation Therapy Oncology Group (RTOG) and the European Organization for Research and Treatment of Cancer (EORTC) 1995'criteria was used. SPSS software (version 20) was used for data analysis. Chi square test was used for comparison of demographic variables and qualitative data.

\section{ObServations And Results}

Over the study period, 33 patients received two fractions of $9 \mathrm{~Gy}$ brachytherapy after EBRT. After the exclusion of two patients who were lost to follow up, 31 patients were included in the present analysis. Patients included in the study group was propensity-matched 1:1 with a control group of same number of patients who completed EBRT with same dose followed by ICRT of 7 Gy in three fractions.

Patients with locally advanced carcinoma of uterine cervix were enrolled in this study and demographic and baseline characteristics were comparable in both groups (shown in table 1), 
Table-I: Patient characteristic $(n=60)$

\begin{tabular}{|l|l|l|}
\hline Characteristics & Arm A (n=31) & Arm B (n=30) \\
\hline Age at diagnosis & \multicolumn{2}{|l|}{} \\
31 to 60 & $26(83)$ & $25(83)$ \\
Above 60 & $5(16)$ & $5(16)$ \\
\hline Early age of marriage ( $\leq 16$ year) & $87 \%$ & $83 \%$ \\
\hline Lower Economic condition & $60 \%$ & $63 \%$ \\
\hline Grand multiparous & $62 \%$ & $56 \%$ \\
\hline Sign and symptom & $25(80)$ & $24(80.0)$ \\
\hline Post Coital Bleeding & $20(64)$ & $18(60.0)$ \\
\hline Intermenstrual bleeding /Postmenopausal bleeding & $20(87)$ & $28(93.3)$ \\
\hline Excessive per vaginal Discharge & $27(8)$ & $12(40.0)$ \\
\hline Pelvic Pain & $10(32)$ & $7(23.33)$ \\
\hline Dysuria & $6(19)$ & $0(0)$ \\
\hline Rectal Pain & $0(0)$ & $18(60.0)$ \\
\hline Loss Of Appetite & $19(61)$ & $23(76.7)$ \\
\hline Anemia & $22(71)$ &
\end{tabular}

Most of the patients were diagnosed as stage IIB disease in both arms, 18(58\%) and 16(53.0\%) patients in Arm A and B respectively.13 patients (41\%) in Arm-A \& 13 patients (43\%) in Arm-B were in Stage IIIB \& there was only 1 patient from stage IVA in ArmB.

At $1^{\text {st }}$ follow up 6 weeks after completion of treatment, complete response was observed in $16(51 \%)$ of Arm-A and 13 (43\%) of Arm-B patients. There was no statistically significant difference in complete and partial response between two arms on the basis of staging ( $p>0.05)$. Then response evaluation was done at $2^{\text {nd }}$ follow up which was at $12^{\text {th }}$ week after completion of treatment. Response was similar like $1^{\text {st }}$ follow up and there was no progression of disease.

At follow up of 6 month (24 weeks) it was observed that $90 \%$ of patients had complete response in Arm A. In Arm B 86\% had complete response. The overall complete remission was $88 \%$. Statistical analysis revealed there was no significant difference in both arms. Then follow up was done at 3 monthly intervals and clinical and radiologic analysis was done upto 3 years.

Table-II: Distribution of the patients according to treatment response at 6 month

\begin{tabular}{|l|l|l|l|}
\hline Response & $\begin{array}{l}\text { Arm A(total=31) } \\
\mathbf{n \%}\end{array}$ & $\begin{array}{l}\text { Arm B(total =30) } \\
\mathbf{n \%}\end{array}$ & Total \\
\hline Complete response & $27(87)$ & $26(86)$ & $53(87)$ \\
\hline Partial response & $4(13)$ & $4(13)$ & $8(13)$ \\
\hline Progressive disease & 0 & 0 & 0 \\
\hline
\end{tabular}

Finally at 3 years follow up, complete response was $75 \%$ in both arms with $77 \%$ for arm A and $73 \%$ for arm B and $\mathrm{p}$ value was not significant 0.913144 .

Table-III: Distribution of the patients according to treatment response at 3 years

\begin{tabular}{|l|l|l|l|c|}
\hline Response & $\begin{array}{l}\text { Arm A(total=31) } \\
\mathbf{n \%}\end{array}$ & $\begin{array}{l}\text { Arm B(total =30) } \\
\mathbf{n \%}\end{array}$ & Total & P value \\
\hline Disease free & $24(77)$ & $22(73)$ & $46(75)$ & 0.91 \\
\hline Local failure & 4 & 5 & $9(14)$ & \\
\hline Distant failure & 3 & 3 & $6(9)$ & \\
\hline
\end{tabular}

The frequencies of acute toxicities related to treatment were a little bit higher in Arm A than that of Arm B but all the toxicities were managed well by conservative treatment. There was no grade III or higher toxicities, treatment discontinuation or hospitalization for toxicity management was not needed during treatment and follow-up period. Most of the patients suffered from rectal and blader toxicities in both arms. 
Table-IV: Distribution of patients according to toxicity (during treatment)

\begin{tabular}{|l|l|l|l|}
\hline \multirow{2}{*}{ Variables } & \multicolumn{2}{l|}{$\begin{array}{l}\text { Group } \\
\text { (Total=61) }\end{array}$} & \multirow{2}{*}{ p value } \\
\cline { 2 - 3 } & Arm-A [n (\%)] & Arm-B [n (\%)] & \\
\hline Skin Reaction & & & \\
\hline $\begin{array}{l}\text { Grade 1 } \\
\text { Grade 2 }\end{array}$ & $\begin{array}{l}10(33.33) \\
8(26.66)\end{array}$ & $\begin{array}{l}9(30) \\
7(23.33)\end{array}$ & 0.967 \\
\hline Vaginal mucositis & & & \\
\hline Grade 1 & $8(26.66)$ & $6(20)$ & 0.746 \\
Grade 2 & $4(13.33)$ & $4(13.33)$ & \\
\hline Bladder toxicity & & & \\
\hline Grade-1 & $12(40.0)$ & $10(33.3)$ & \\
Grade 2 & $8(26.66)$ & $6(20)$ & 0.878 \\
\hline Rectal toxicity/ & & & 0.370 \\
\hline Grade-1 & $9(30)$ & $10(33.3)$ & \\
Grade 2 & $10(33.33)$ & $6(20)$ & \\
\hline Haematologic toxicities & & & 0.473 \\
\hline Grade 1 & $10(3)$ & $11(37)$ & \\
\hline Grade 2 & $5(17)$ & $3(10)$ & \\
\hline
\end{tabular}

During follow up at 3 years after completion of treatment 3 patients in arm A and 2 patients in arm B developed grade II bladder toxicities and only 5 patients in arm A and 3 patients in arm B developed rectal grade
II toxicities,. The late bladder and rectal toxicity was higher in arm A than arm B but it was not statistically significant ( $\mathrm{p}$ value 0.2899 ).

Table-V: Distribution of patients according to late toxicities (at 3 years)

\begin{tabular}{|l|l|l|l|}
\hline Toxicity (grade 2) & $\begin{array}{l}\text { Arm A(total=31) } \\
\text { n(\%) }\end{array}$ & $\begin{array}{l}\text { Arm B (total=30) } \\
\text { n(\%) }\end{array}$ & p value \\
\hline Bladder & $3(9 \%)$ & $2(6.66 \%)$ & \multirow{2}{*}{0.928} \\
\hline Rectal & $5(16 \%)$ & $3(10)$ & \\
\hline
\end{tabular}

\section{DiSCUSSION}

For locally advanced carcinoma cervix radiotherapy is the main modality of treatment and intracavitary brachytherapy is an essential part of it. In recent years, owing to the obvious physical advantages of shortened treatment time and better geometric placement HDR brachytherapy has gained popularity. No clear consensus of the appropriate number of fractions or appropriate dose per fraction has been reached. Various fractionation schemes have been used experimentally in search of the optimal technique. The number of fractions has varied from as low as 1 to as many as 16 . The dose per fraction to point $\mathrm{A}$ has varied from 3 to $17 \mathrm{~Gy} /$ fraction [7-9].

Our present study was done using the HDR Microselectron with an Iridium 192 source and the HDR Microselectron Nucleotron applicator. We used a dose of $9 \mathrm{~Gy} /$ fraction of 2 fractions in Arm A and 3 fraction of $7 \mathrm{~Gy} /$ fraction in Arm B. The effects and toxicities were observed during and upto three years after completion of treatment. Both clinical examination and radiologic study (USG of W/A, CT scan of W/A) was done to see the presence of any microscopic residual disease or recurrence. Complete remission was observed in $90 \%$ of patients in arm A and it was $86 \%$ in arm B, the overall complete response was $88 \%$ at 6 month after completion of treatment. Statistical analysis revealed there was no significant difference between two arms. at 3 years follow up, complete response was $75 \%$ in both arms with $77 \%$ for arm A and $73 \%$ for arm $\mathrm{B}$ and $\mathrm{p}$ value was not significant.

The most prevalent acute toxicities in both the arms were bladder and rectum related toxicities, skin reaction, and vaginal mucositis. In arm A total 18 patients $(60 \%)$ developed grade I and grade II skin toxicities whereas in arm B 16 patients (53.33\%) developed skin reaction. Vaginal mucositis was present in 12 patients (40\%) in arm A and 10 patients (33.33\%) in arm B. Regarding bladder and rectal toxicities 20 patients $(65 \%)$ in arm A and $16(53 \%)$ patients in arm B developed bladder toxicities. $19(61 \%)$ patients in arm A and $16(53 \%)$ patients in arm B developed grade I and grade II rectal toxicities. No patient in both arms developed grade III or grade IV toxicity and there was no interruption of treatment due to toxicity. Although treatment related toxicities were slightly more in arm A and was managed well but it was not statistically significant ( $\mathrm{p}$ value $<0.05$ ).

During follow up at 3 years, $3(9 \%)$ patients in arm A and 2 (7\%) patient in arm B developed grade II bladder toxicities and only $5(16 \%)$ patients in arm a developed rectal grade II toxicities and $3(10 \%)$ patients rectal toxicity in arm B. 
In different studies it is effectively shown that in choosing the number HDR fraction and consequently the dose per fraction, it is the prescribed dose received by the critical organs that is important. If the critical organ receive a smaller percentage of the point A dose, we can use larger dose per fraction without increasing morbidity [8-10]. The advantage of using fewer fractions is patient convenience and improved patient compliance. Two fractions of 9 Gy brachytherapy can be completed in less time and less exposure than three fractions of $7 \mathrm{~Gy}$. Reducing the risk of multiple exposures to anesthetic agents and minimizing the number of hospital attendance makes this schedule cost effective. This schedule also reduces the patient load in radiotherapy centers to some extent which is a major consideration in a developing country like ours where radiotherapy centers are overburdened with cancer patients.

\section{CONCLUSION}

HDR brachytherapy 2 fractions of 9 Gy after concurrent chemoradiotherapy is equally effective in comparison with the brachytherapy of 3 fractions of 7 Gy after concurrent chemoradiotherapy for the control of locally advanced carcinoma cervix but more convenient regarding time and cost.

\section{REFERENCE}

1. Ferlay J, Soerjomataram I, Dikshit R, Eser S, Mathers C, Rebelo M, Parkin DM, Forman D, Bray F. Cancer incidence and mortality worldwide: sources, methods and major patterns in GLOBOCAN 2012. International journal of cancer. 2015 Mar 1;136(5).

2. Cancer Registry Report, National Institute of Cancer Research and Hospital, Mohakhali, Dhaka, 2012-2014, pp 08.
3. Forman D, de Martel C, Lacey CJ, Soerjomataram I, Lortet-Tieulent J, Bruni L, Vignat J, Ferlay J, Bray F, Plummer M, Franceschi S. Global burden of human papillomavirus and related diseases. Vaccine. 2012 Nov 20; 30:F12-23.

4. Bruni L, Barrionuevo-Rosas L, Albero G, Serrano B, Mena M, Gómez D. Human Papillomavirus and Related Diseases in the World. Summary Report. ICO Information Centre on HPV and Cancer (HPV Information Centre) 2016. [Last accessed on 2016 Nov 24].

5. Colombo N, Carinelli S, Colombo A, Marini C, Rollo D, Sessa C, ESMO Guidelines Working Group. Cervical cancer: ESMO Clinical Practice Guidelines for diagnosis, treatment and follow-up. Annals of Oncology. 2012 Oct 1;23(suppl_7):vii27-32.

6. Barrett A, Morris S, Dobbs J, Roques T. Practical radiotherapy planning. CRC Press; 2009 Jun 26.

7. Patel FD, Sharma SC, Negi PS, Ghoshal S, Gupta BD. Low dose rate vs. high dose rate brachytherapy in the treatment of carcinoma of the uterine cervix: a clinical trial. International Journal of Radiation Oncology* Biology* Physics. 1994 Jan 15;28(2):335-41.

8. Viswanathan AN, Beriwal S, Jennifer F, Demanes DJ, Gaffney D, Hansen J, Jones E, Kirisits C, Thomadsen B, Erickson B. American Brachytherapy Society consensus guidelines for locally advanced carcinoma of the cervix. Part II: high-dose-rate brachytherapy. Brachytherapy. 2012 Jan 1;11(1):47-52.

9. Patel FD, Rai B, Mallick I, Sharma SC. High-doserate brachytherapy in uterine cervical carcinoma. International Journal of Radiation Oncology* Biology* Physics. 2005 May 1;62(1):125-30.

10. Fowler JF. The Radiobiology of brachytherapy. Brachytherapy HDR and LDR. 1990:121-37. 